\title{
Effect of DC Filters on Selection of Fault Discriminator for Unit Protection of Monopolar HVDC Transmission System
}

\author{
Soma Deb ${ }^{1}$, H. K. Verma ${ }^{2}$ \\ ${ }^{1,2}$ Electrical and Electronics Engineering Department, School of Engineering and Technology, Sharda University, \\ Greater Noida, India
}

\begin{tabular}{l}
\hline Article Info \\
\hline Article history: \\
Received Oct 16, 2018 \\
Revised Apr 30, 2019 \\
Accepted Aug 29, 2019 \\
\hline
\end{tabular}

\section{Keyword:}

Cascaded double-tuned dc filter Fault discriminator Parallel double-tuned dc filter PSCAD/EMTDC

Triple-tuned dc filter

\begin{abstract}
Various research works reported on the unit protection of monopolar highvoltage direct-current transmission system assumed either no dc filter or a certain type of dc filter in the system. From the survey of literature, it appears that no study has been made to evaluate the effect of the type of dc filter on the system performance and consequent effect on the selection of fault discriminator for development of protection schemes. The work reported in this paper aims at selection of suitable fault discriminators for unit protection of HVDC transmission system in the presence of three different types of dc filter. The study has been carried out on a $500-\mathrm{kV}$ line- commutated-converterbased monopolar HVDC system equipped with any of the three filters, namely, cascaded double-tuned, parallel double-tuned or triple-tuned filter. Simulation has been carried out with PSCAD/EMTDC. Critical analysis of the simulation results shows how the type of the dc filter influences the choice of fault discriminator.
\end{abstract}

Copyright $\left({ }_{0} 2019\right.$ Institute of Advanced Engineering and Science. All rights reserved.

\section{Corresponding Author:}

Soma Deb,

Electrical and Electronics Engineering Department,

School of Engineering and Technology, Sharda University,

Greater Noida, India.

Email: soma.deb@sharda.ac.in

\section{INTRODUCTION}

High-voltage direct-current (HVDC) transmission systems are now widely used for interconnection of far-away load centers due to their both high efficiency and competitive costs [1-2]. The other well-known advantages of HVDC transmission system include bulk power transmission over longer distances, and interconnection of two asynchronous systems [3].

Protection of HVDC transmission line plays a vital role in the overall security of an HVDC transmission system, considering high probability of occurrence of faults on the line. This high probability is attributed to long length of the lines and the rough terrain through which such lines run [4-5]. A fast protection is essential because of the serious consequences of a prolonged fault. Presently, in many of the HVDC projects, travelling wave-based protection is used as the primary protection. However, reduction in the relay sensitivity at high resistance faults and the need of high accuracy of sampling rate are two important shortcomings of this technique [6-7]. To overcome these problems, considerable research has been made on protection based on transient principles, where the attenuation effects the dc line boundary composing of a smoothing reactor and a dc filter have been used for discrimination between internal and external faults [8-11].

The performance of protection scheme of a HVDC transmission system is largely determined by the selection of an appropriate fault discriminator. The choice of fault discriminator is made on the basis of a detailed performance study of the given HVDC system in terms of the system variables of interest [12]. The system performance in turn is affected by the type of dc filter connected in the system. However, to the author's best knowledge, no study has been made to evaluate this effect. 
Various research works reported on the unit protection of monopolar HVDC transmission system have assumed either no dc filter or a certain type of dc filter [9-11,13-19]. Reference [9] proposed a unit protection scheme with transient energy as the fault discriminator and no dc filter was considered. This technique shows a reduction in sensitivity with increase in fault resistance. Reference [10] proposed an algorithm with transient harmonic current as fault discriminator and the filter considered was cascaded double-tuned type, the limitation of which was again reduction in the sensitivity with increase in fault resistance. Reference [11] puts forward a unit protection scheme using voltage as the fault discriminator and triple-tuned dc filter. However, the value of the normalized voltage-change-rate, which is used as the fault discriminator, reduces with increase in fault resistance and hence the sensitivity of the scheme is low for high values of fault resistance. Reference [13] makes use of certain characteristics of fault component of current for fault detection and classification and does not consider any dc filter. Reference [14] puts forward a protection scheme using differential current as the fault discriminator while the dc filter considered was triple-tuned type. Although it shows an improved performance over the conventional differential current protection in terms of sensitivity, it is applicable only for back-up protection as stated by the authors. Reference [15] proposes a protection scheme based on the voltage across the dc reactor with no dc filter under consideration. Reference [16] proposes a protection technique using the second harmonic voltage in AC system bus and no dc filter was considered. A differential protection scheme based on the compensation of distributed capacitive current is proposed in [17]. Butterworth low-pass filter has been considered in this technique. Reference [18] proposes a protection scheme based on the specific frequency current of triple tuned dc filter. A travelling wave-based protection scheme for double circuit transmission line equipped with triple tuned dc filter is proposed in [19].

A critical study of the unit protection schemes proposed in references [9-11,14] was made in reference [12]. It was observed that these schemes have certain limitations which result from their common feature of communicating the measured value of a certain variable from one end of the line to the farther end. Reference [12] attempted to overcome these limitations by transmitting only the sign of the variable and made a detailed investigation on the selection of these variables for fault discrimination. However, this study too was limited to only one type of dc filter, namely cascaded double-tuned filter. The present paper considers three types of dc filters and analyzes the suitability of different system variables as fault discriminators for unit protection.

The next section of this paper gives some details of (line-commutated converter) LCC-HVDC system simulated on PSCAD ${ }^{\mathrm{TM}} / \mathrm{EMTDC}^{\mathrm{TM}}$ to obtain the time variations of three system variables, namely incremental current, incremental power and transient energy. This section also presents observations for HVDC system with cascaded double-tuned dc filter on the basis of the detailed results reported in reference [12]. Detailed results for the system response with parallel double--tuned dc filter and triple-tuned dc filter, along with their analyses are presented in Section 3 and Section 4 respectively. Overall conclusions of the study are presented in the last section. The configuration and component values of cascaded double-tuned filter assumed were the same as given in [12] and those of the remaining two types of dc filters are given in Appendix.

\section{TEST SYSTEM FOR SIMULATION}

The CIGRE (Conseil International des Grands Réseaux Électriques, or International Council on Large Electric Systems) benchmark model for monopolar HVDC system has been used for the study and the simulation software used is PSCAD ${ }^{\mathrm{TM}} / \mathrm{EMTDC}^{\mathrm{TM}}$ [20]. Important parameters of the test system and the simulation diagram are shown in Table 1 and Figure 1, respectively. A sampling frequency of $2 \mathrm{kHz}$ was used in the simulation.

The dc voltages and currents were measured at the two extreme ends $\mathrm{M}$ and $\mathrm{N}$ of the dc transmission line. Internal (dc) faults were simulated at three points on the line: $\mathrm{DF}_{1}$ at the rectifier end, $\mathrm{DF}_{2}$ at the middle of the line and $\mathrm{DF}_{3}$ at the inverter end. External (ac) faults were assumed at the terminals of the ac sources 1 and 2, as illustrated in Figure 1.

Table 1. Parameters of Test System

\begin{tabular}{lc}
\hline \multicolumn{1}{c}{ Parameters } & Rating values \\
\hline Voltage rating of AC Source 1 & $345 \mathrm{kV}$ \\
Voltage rating of AC source 2 & $230 \mathrm{kV}$ \\
Frequency of AC sources & $50 \mathrm{~Hz}$ \\
Length of DC transmission line & $800 \mathrm{~km}$ \\
Current rating of dc transmission line & $2 \mathrm{kA}$ \\
Voltage rating of dc transmission line & $500 \mathrm{kV}$ \\
\hline
\end{tabular}

IJEEI, Vol. 7, No. 3, Sep 2019: $393-404$ 


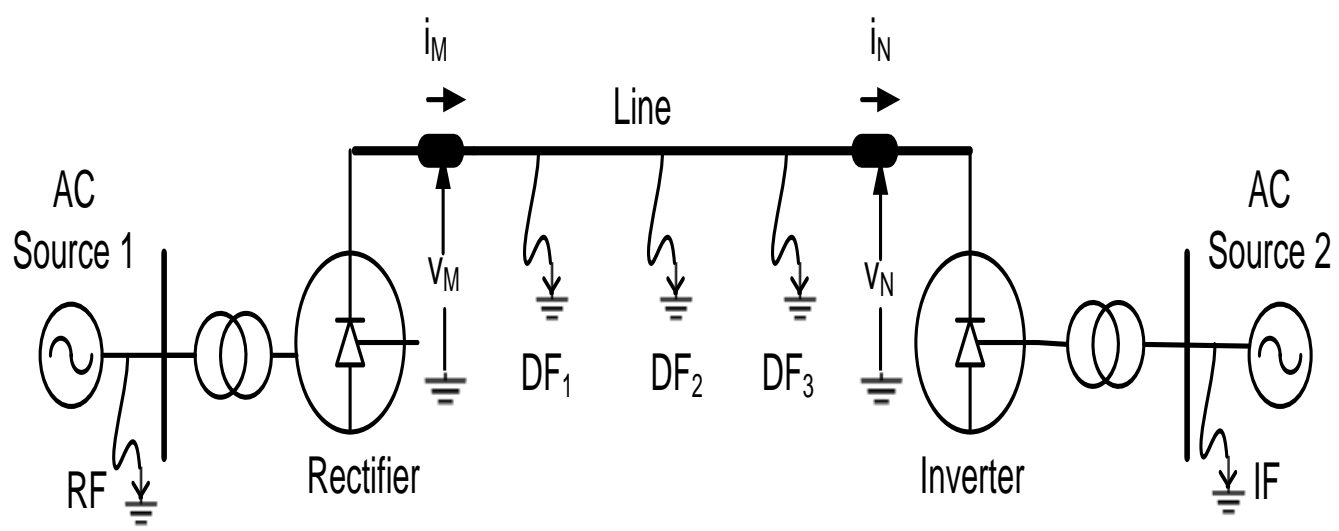

Figure 1. Simulation Diagram

Simulation study and complete analysis of the response of HVDC system equipped with cascaded double-tuned dc filter has been carried out in [12]. Based on the same, the following observations have been made regarding selection of fault discriminator:

i No useful information can be obtained from the incremental voltage response curves for discriminating internal (dc) faults from external (ac) faults.

ii Signs of incremental current at the two ends together can be used to discriminate between internal and external faults.

iii Observation at (ii) above applies equally well to the signs of incremental power and transient energy.

iv Signs of incremental impedance at the two ends, like incremental voltage, do not provide any useful information for fault discrimination.

In summary, any of the incremental current, incremental power and transient energy can be used as fault discriminator.

\section{RESPONSE FOR PARALLEL DOUBLE-TUNED DC FILTER}

Response of the same system in the presence of parallel double-tuned dc filter (instead of cascadeddouble-tuned filter) at both ends was carried out to find suitable fault discriminator (s). In view of the findings in [12] for cascaded double-tuned dc filter, the possibility of using incremental voltage and incremental impedance as fault discriminators was ruled out. Results for the remaining three variables and their analysis are given below.

\subsection{Response in Terms of Incremental Current}

Response of the HVDC system in terms of incremental current is shown in Figure 2. As seen in Figure 2 (a), the incremental currents at the two ends of the line, $\Delta \mathrm{I}_{\mathrm{M}}$ and $\Delta \mathrm{I}_{\mathrm{N}}$, have some oscillations at the fault end only for dc line-end faults $\left(\mathrm{DF}_{1}\right.$ and $\left.\mathrm{DF}_{3}\right)$, whereas the incremental current curves are free from such oscillations for fault at the mid-pint of the line $\left(\mathrm{DF}_{2}\right)$. For external ac faults, the incremental current curves are free from such oscillations, as shown in Figure 2 (b). Presence of high frequency components in the incremental current at the fault end negates consideration of this variable as fault discriminator to discriminate between line-end dc faults and external ac faults.

\subsection{Response in Terms of Incremental Power}

Figure 3 (a) shows incremental power curves $\left(\Delta \mathrm{P}_{\mathrm{M}}\right.$ and $\left.\Delta \mathrm{P}_{\mathrm{N}}\right)$ for three internal fault locations $\left(\mathrm{DF}_{1}, \mathrm{DF}_{2}\right.$ and $\mathrm{DF}_{3}$ ) while Figure 3 (b) shows the same for two external fault locations (RF and IF). It can be seen from Figure 3 (a) that for dc fault DF1 near end $\mathrm{M}$ the incremental power curve for end $\mathrm{M}, \Delta \mathrm{P}_{\mathrm{M}}$, oscillates between positive and negative values and similarly for dc fault DF2 near end $\mathrm{N}$, the incremental power curve for end $\mathrm{N}, \Delta \mathrm{P}_{\mathrm{N}}$, also oscillates between positive and negative values. Hence incremental power also cannot be considered as a good fault discriminator. 


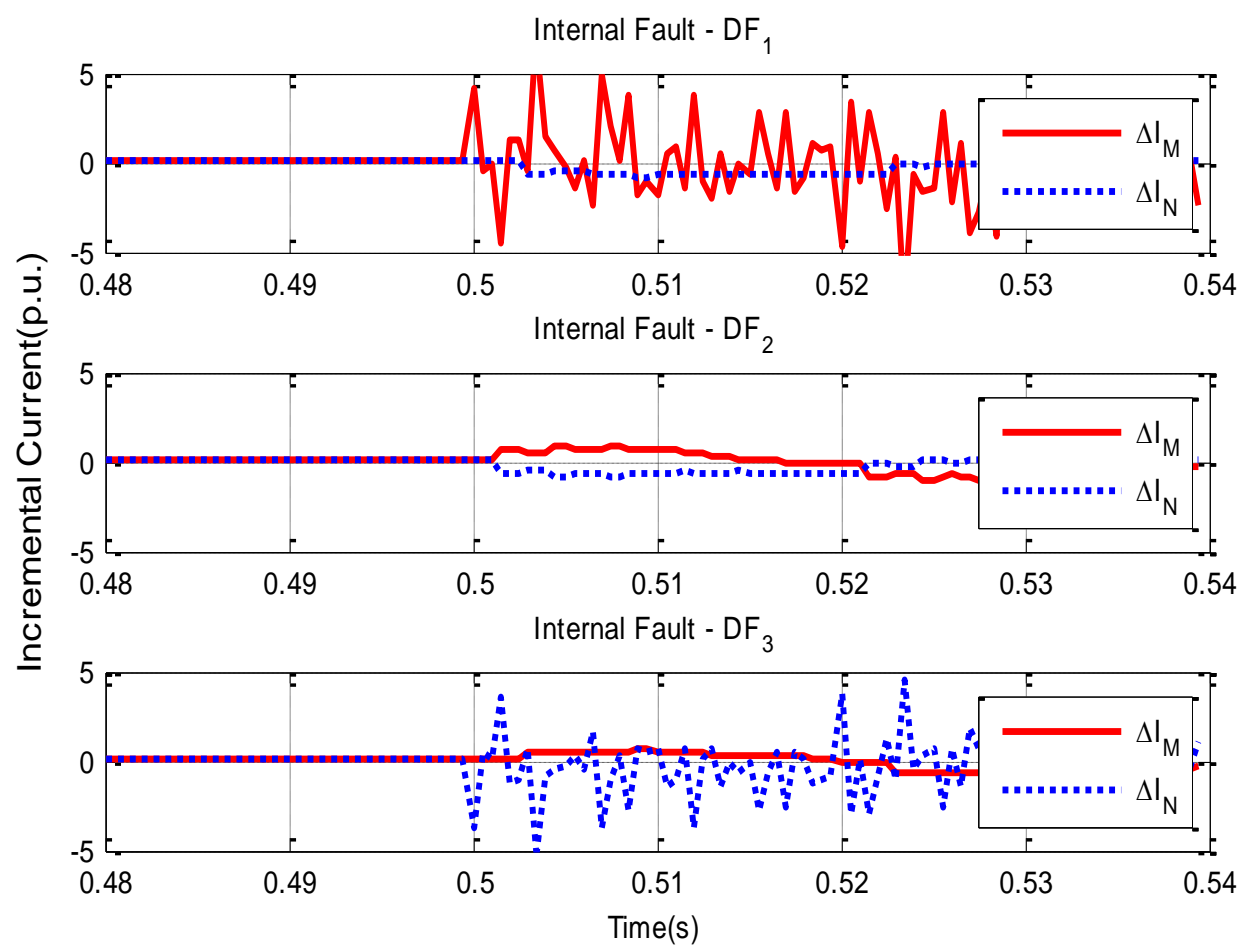

(a)
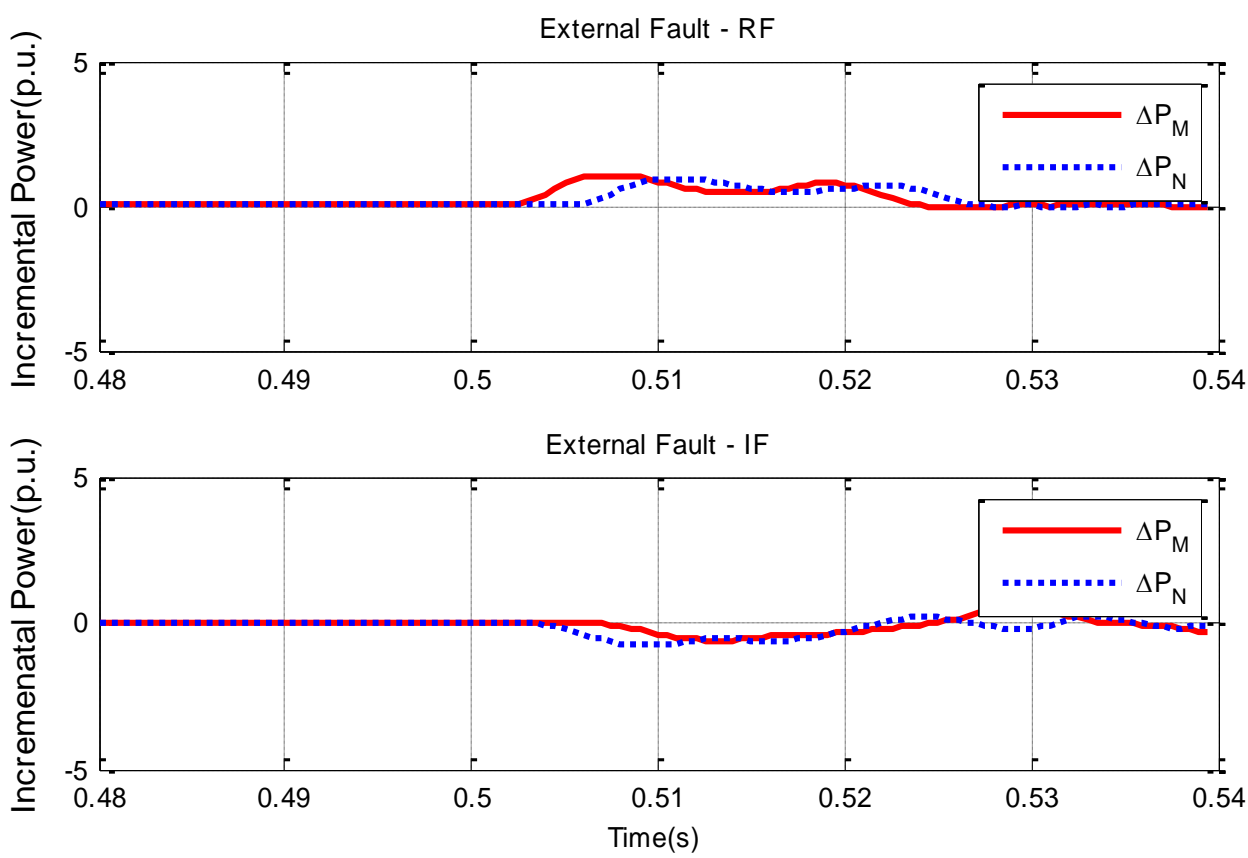

(b)

Figure 2. System Response in terms of incremental current for (a) internal faults $-\mathrm{DF}_{1}, \mathrm{DF}_{2}$ and $\mathrm{DF}_{3}$, (b) external faults- rectifier fault (RF) and inverter fault (IF) 


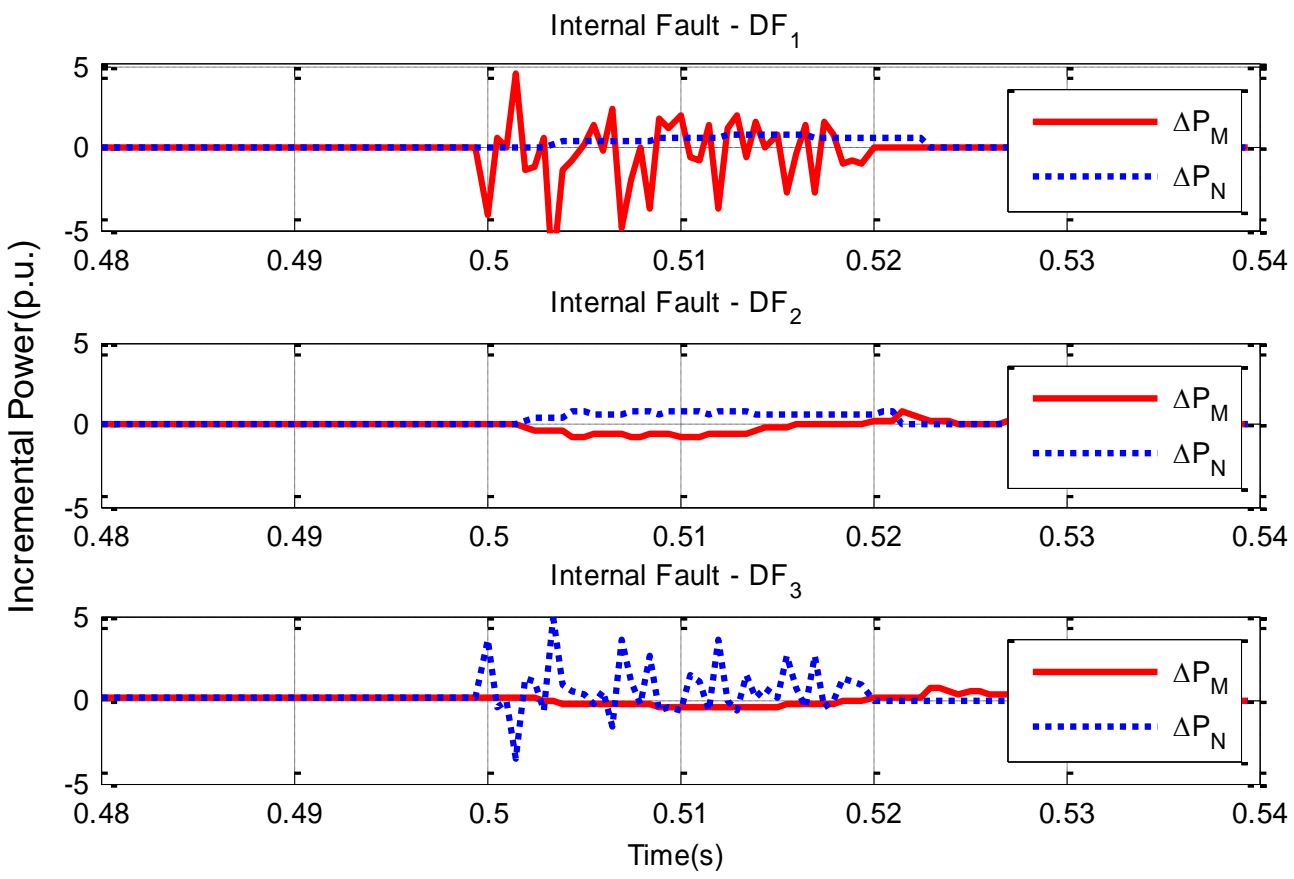

(a)
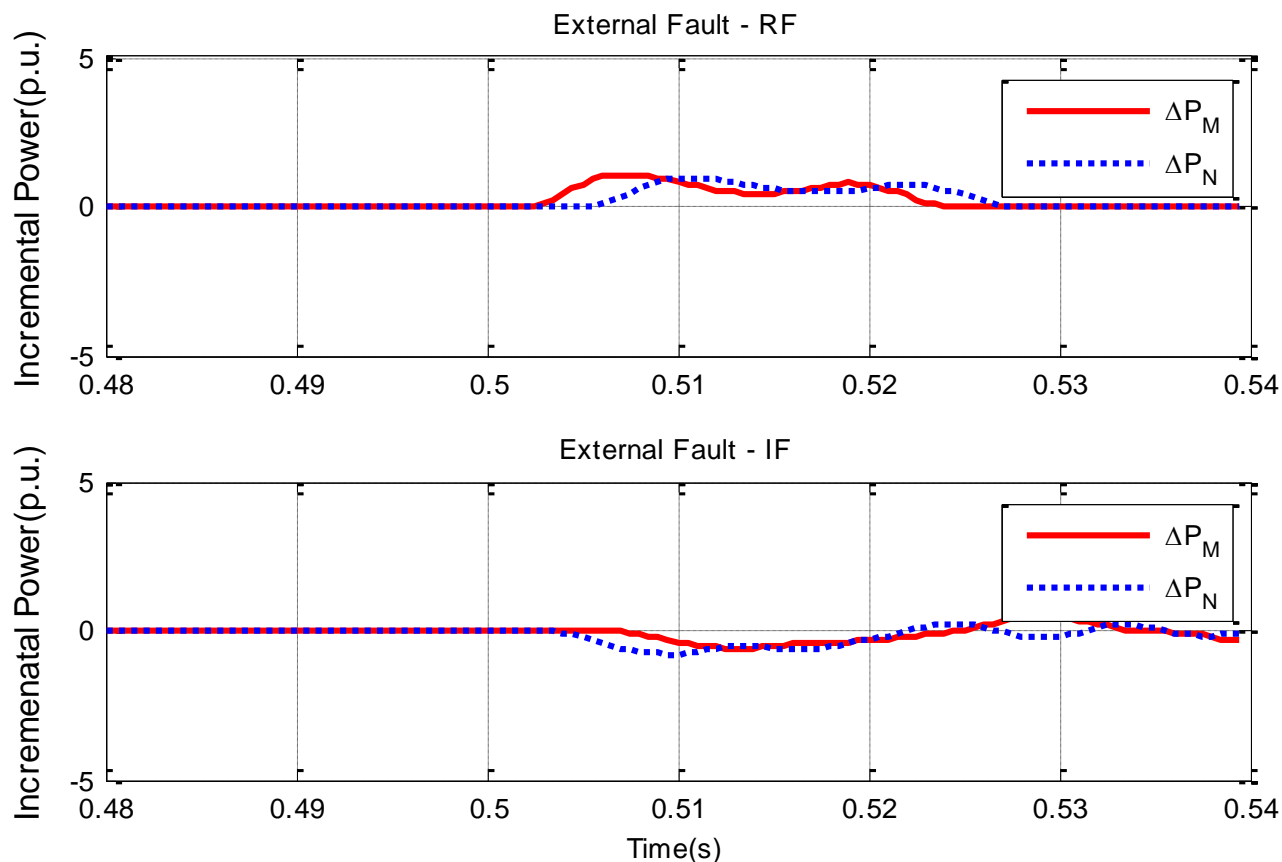

(b)

Figure 3. System response in terms of incremental power for (a) internal faults $-\mathrm{DF}_{1}, \mathrm{DF}_{2}$ and $\mathrm{DF}_{3}$, (b) external faults- rectifier fault (RF) and inverter fault (IF).

\subsection{Response in Terms of Transient Energy}

Figure 4 shows five curves of system response on solid dc faults $\left(\mathrm{DF}_{1}, \mathrm{DF}_{2}, \mathrm{DF}_{3}\right)$ and ac faults $(\mathrm{RF}$ and IF) in the presence of parallel double-tuned dc filter at each end. The curves for dc faults reveal that the transient energy is positive at one end and negative at the other end for a duration long enough to detect the fault. The curves in part (b) of Figure 4 show that the transient energy at both ends is positive in case of ac fault at rectifier end and both negative for ac fault at inverter end. Thus, transient energy can very well discriminate (a) between internal dc faults and external ac fault, and (b) between rectifier end and inverter end ac faults. 


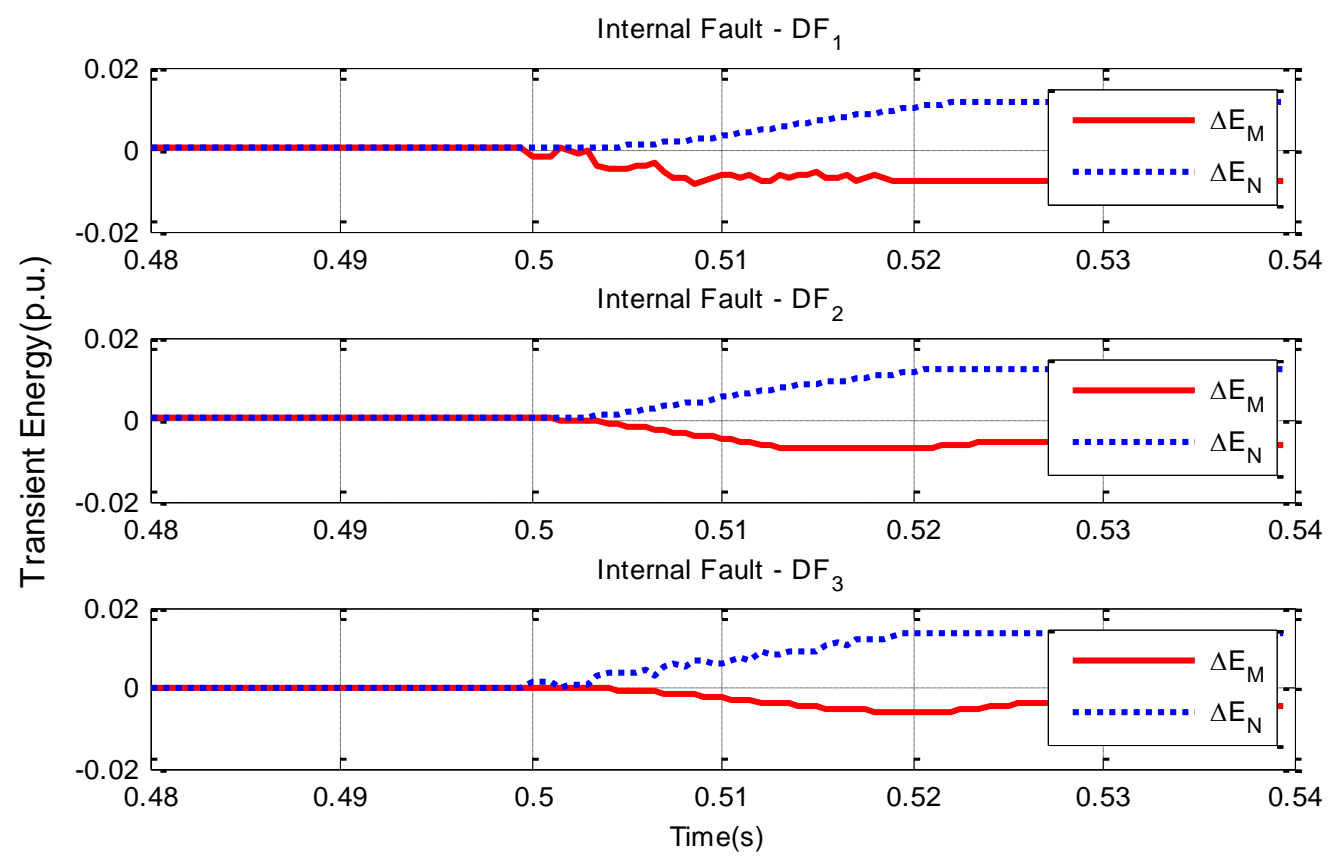

(a)
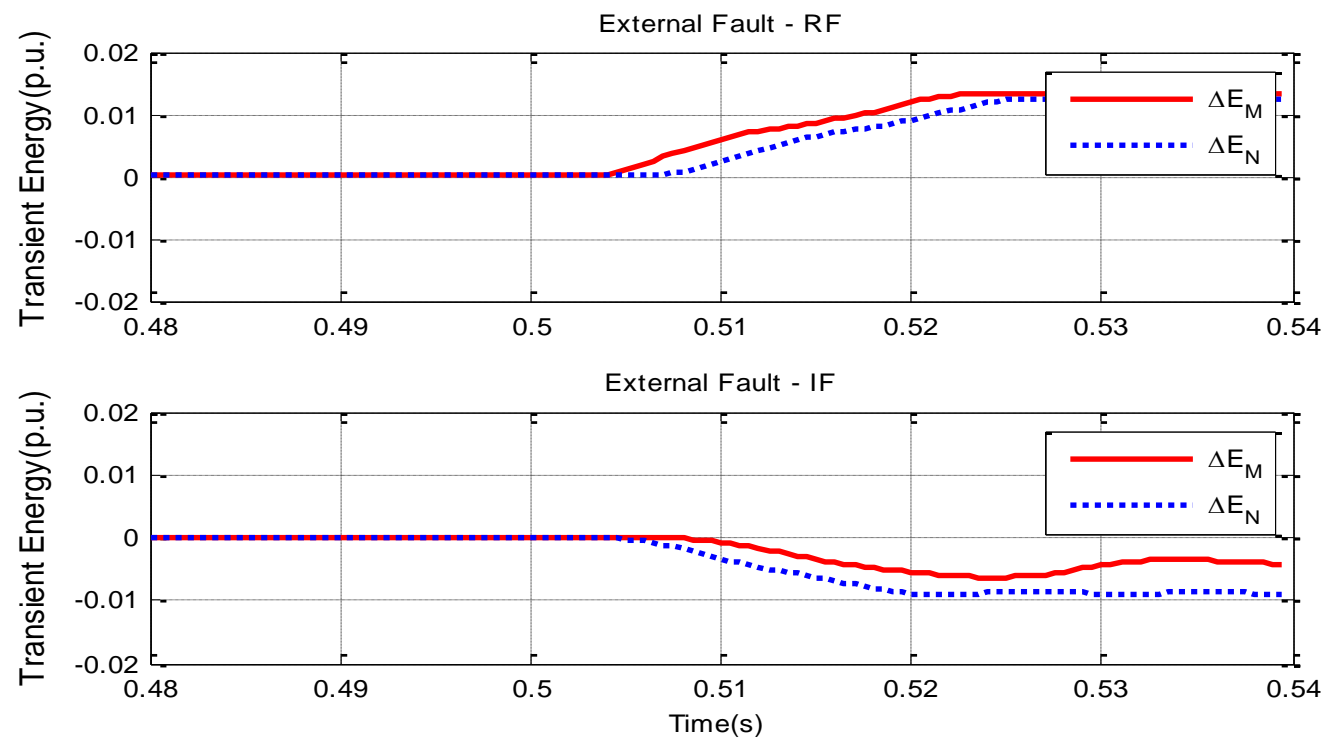

(b)

Figure 4. System Response in terms of change in transient energy for (a) internal faults $-\mathrm{DF}_{1}, \mathrm{DF}_{2}$ and $\mathrm{DF}_{3}$, (b) external faults- rectifier fault (RF) and inverter fault (IF).

\subsection{Selection of Fault Discriminator for HVDC System with Parallel-Double-Tuned DC Filter}

The above analysis leads to the following observations:

i Incremental current and incremental power cannot differentiate line-end dc faults from external ac faults, and hence cannot be used as fault discriminator.

ii Transient energy can differentiate all internal dc faults from external faults and hence seems to be a suitable fault discriminator. 


\section{RESULT FOR TRIPLE-TUNED DC FILTER}

In this case also, the HVDC system response has been studied in terms of incremental current, incremental power and transient energy.

\subsection{Response in Terms of Incremental Current}

Figure 5 shows the system response in terms of incremental current to faults at different locations in HVDC system. A closed examination of the response curves for line end dc faults $\left(\mathrm{DF}_{1}\right.$ and $\left.\mathrm{DF}_{3}\right)$ in Figure 5 (a), reveals that the incremental current is mostly positive during the first $10 \mathrm{~ms}$ period but becomes zero or slightly negative for one sample duration. The incremental current at the other end is continuously negative during the same period. A delay of 1 sample period $(0.5 \mathrm{~ms})$ can be inserted in the relay response to ignore the negative spike. There is no such issue of spike in the response curves for ac faults and mid-point dc faults. Therefore, incremental current can be used as a fault discriminator by adding a delay of $0.5 \mathrm{~ms}$ in the relay response.

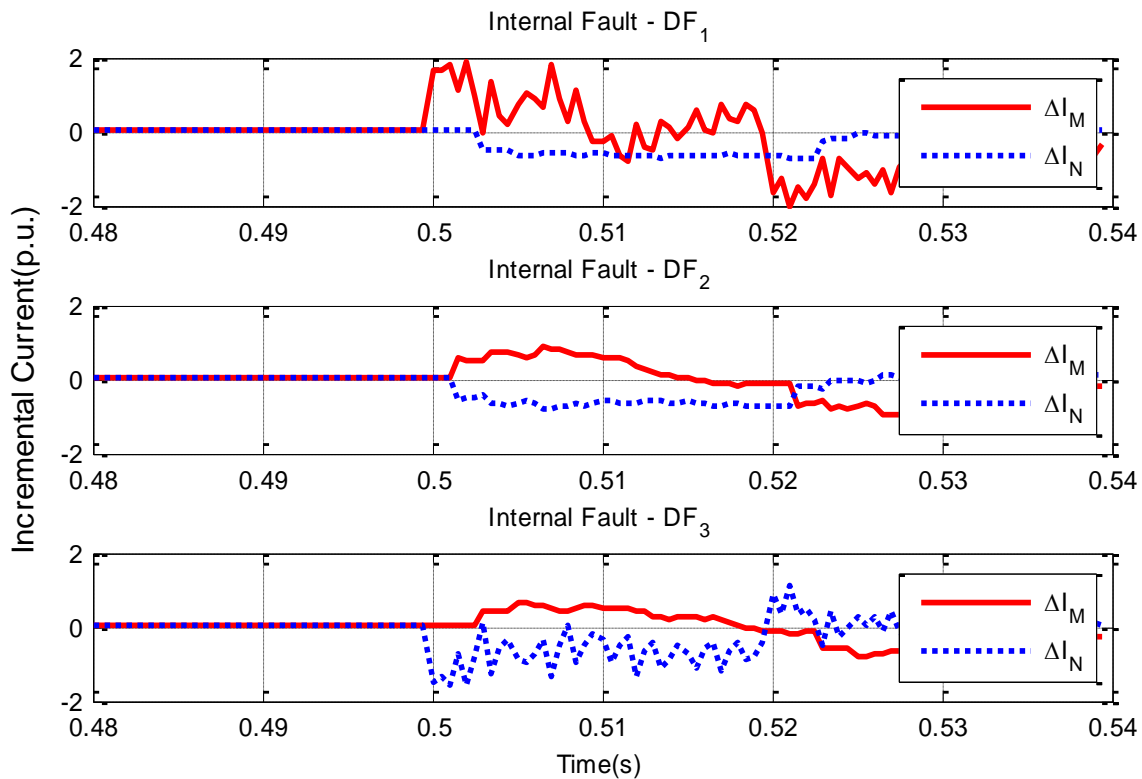

(a)
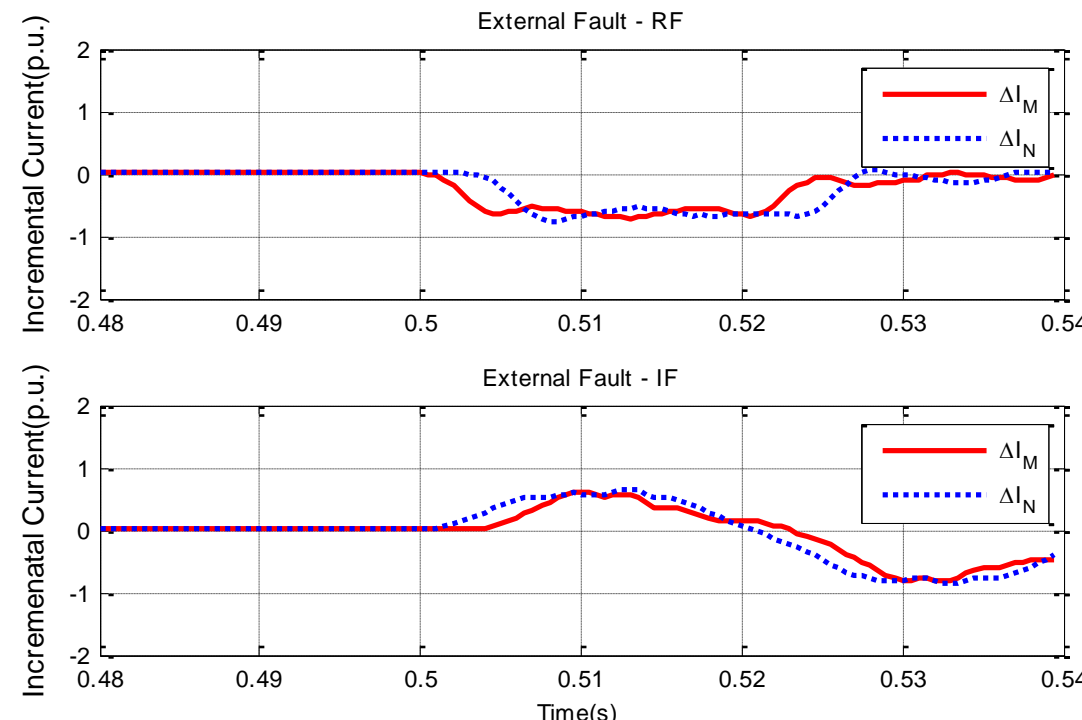

(b)

Figure 5. System Response in terms of incremental current for (a) internal faults $-\mathrm{DF}_{1}, \mathrm{DF}_{2}$ and $\mathrm{DF}_{3},(\mathrm{~b})$ external faults- rectifier fault (RF) and inverter fault (IF). 


\subsection{Response in Terms of Incremental Power}

Response curves for incremental power, as shown in Figure 6, are similar to those for incremental current. A delay of $0.5 \mathrm{~ms}$ can take care of the negative spike in the response curves as proposed for incremental current.

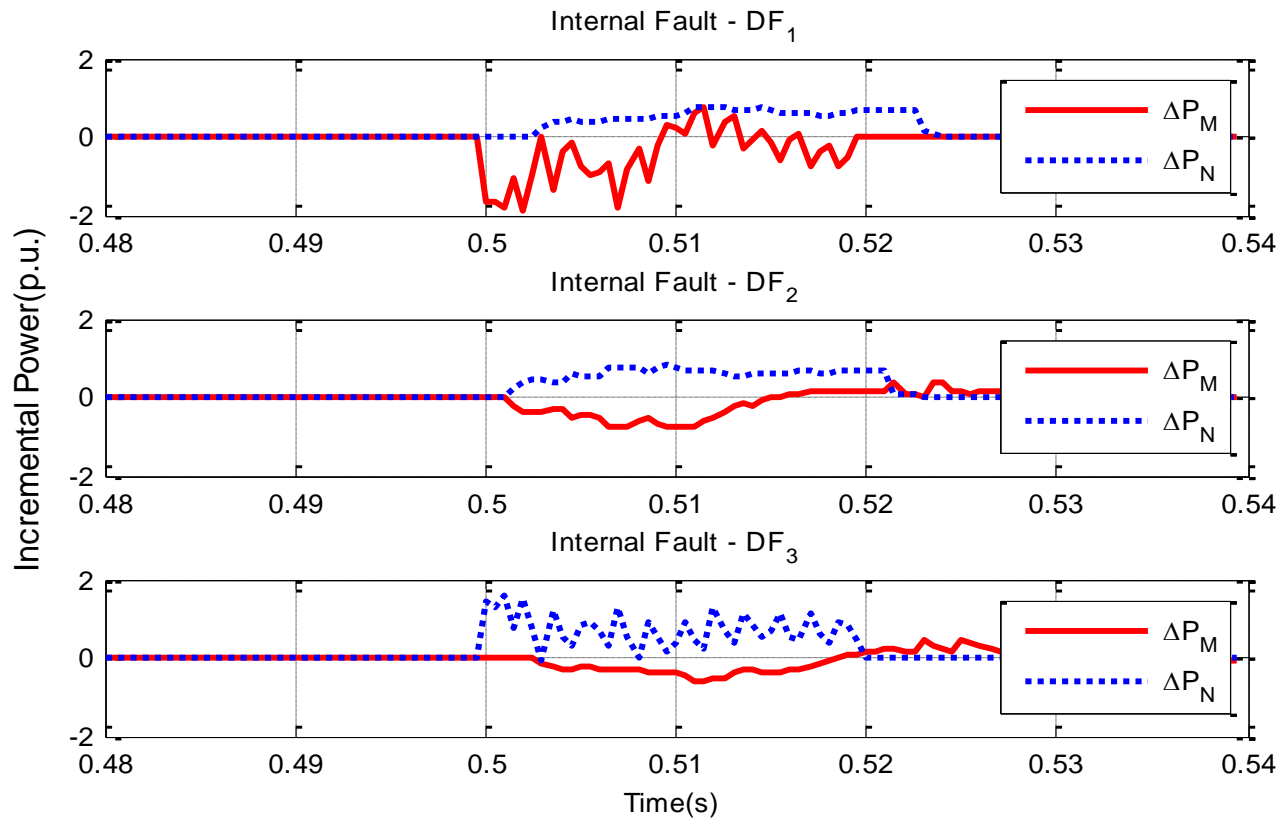

(a)
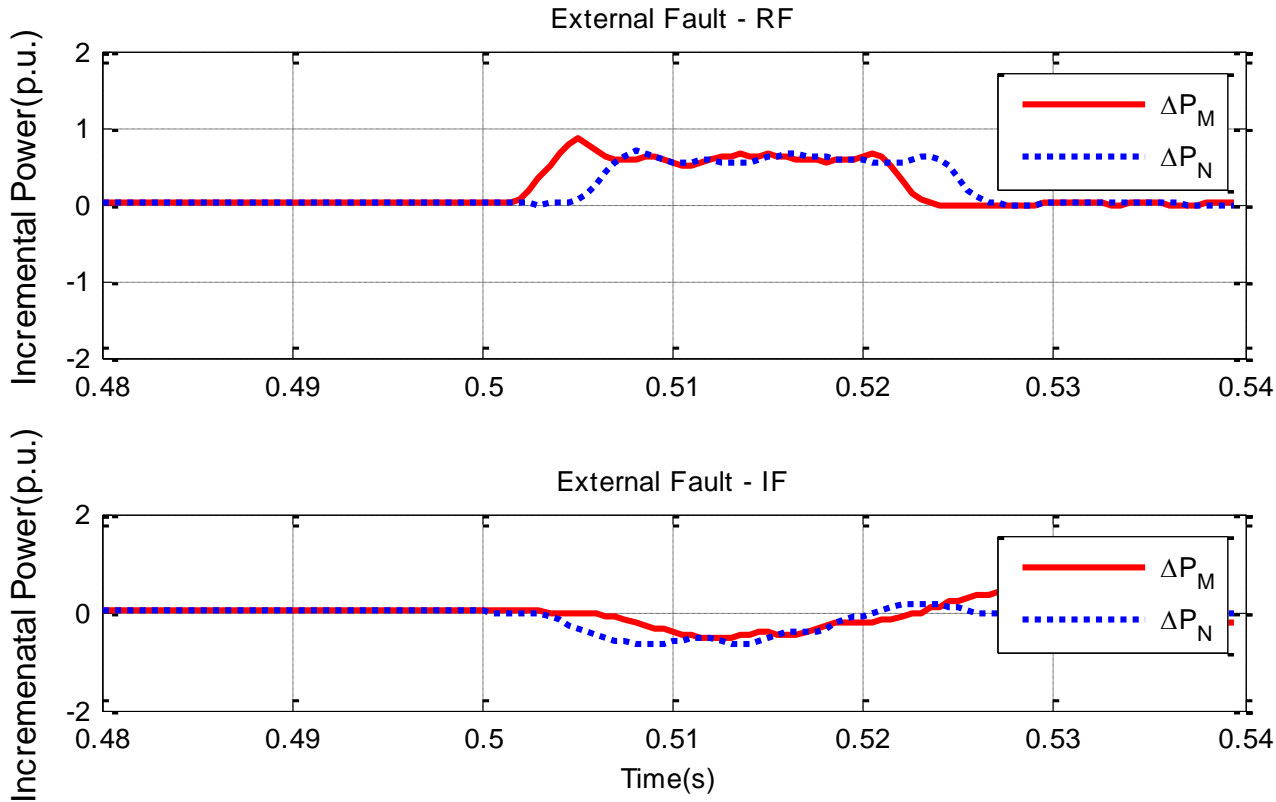

(b)

Figure 6. System Response in terms of incremental power for (a) internal faults $-\mathrm{DF}_{1}, \mathrm{DF}_{2}$ and $\mathrm{DF}_{3}$, (b) external faults- rectifier fault (RF) and inverter fault (IF).

\subsection{Response in Terms of Transient Energy}

The response curves, as shown in Figure 7, resemble those with single, parallel double-tuned and cascaded double dc filters. Therefore, transient energy is a good fault discriminator for HVDC system with triple-tuned dc filter also. 


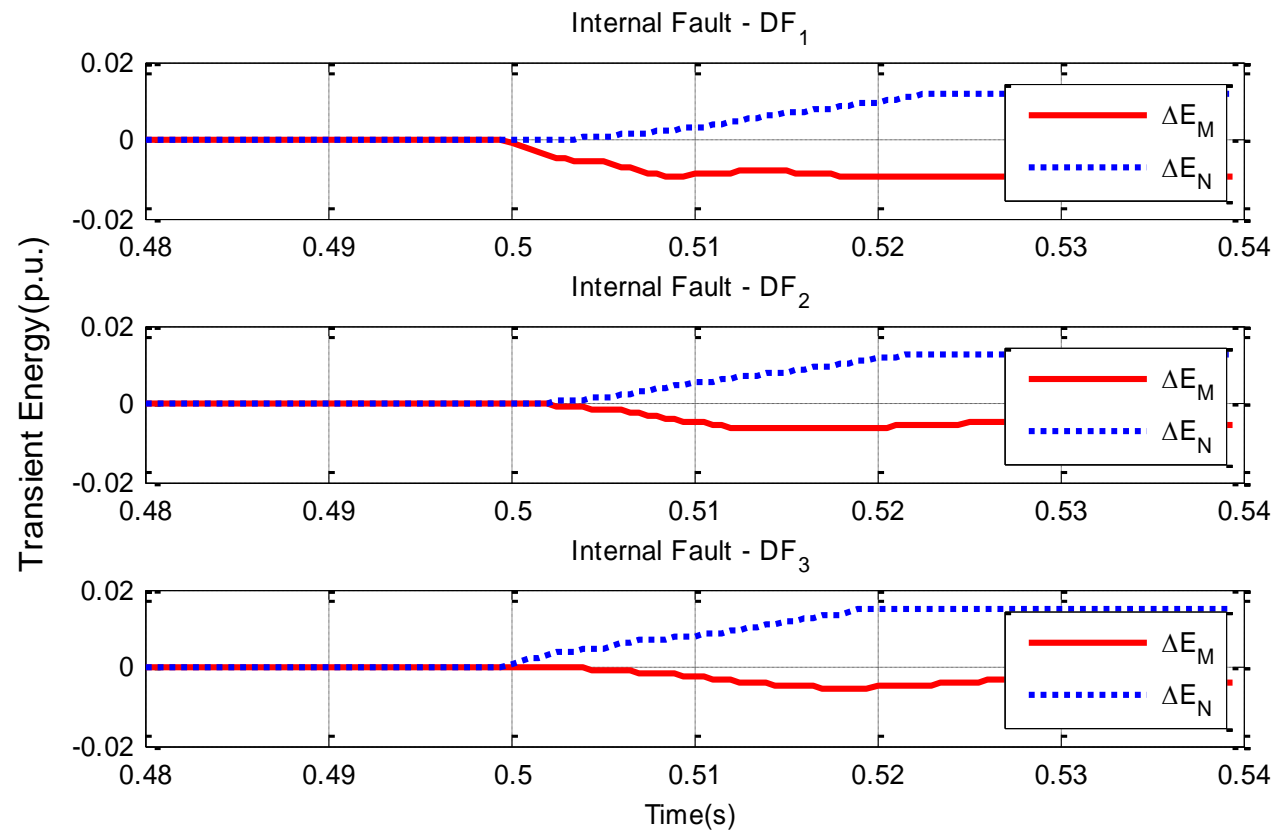

(a)
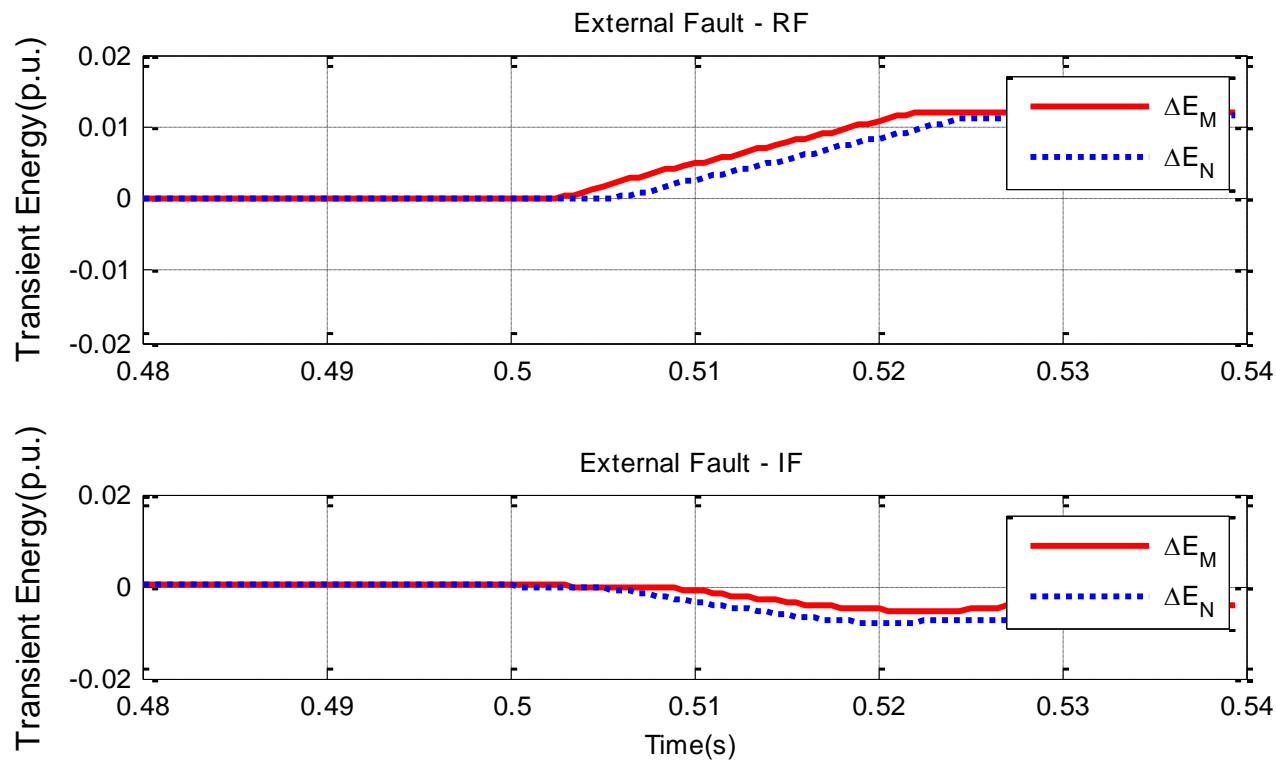

(b)

Figure 7. System Response in terms of transient energy for (a) internal faults $-\mathrm{DF}_{1}, \mathrm{DF}_{2}$ and $\mathrm{DF}_{3},(\mathrm{~b})$ external faults- rectifier fault (RF) and inverter fault (IF).

\subsection{Selection of Fault Discriminator for HVDC System with Triple-Tuned DC Filter}

The following observations can be made based on the above results:

i. Incremental current and incremental power presents a small problem in discrimination because of the presence of a negative spike in the initial period. The solution proposed is to insert a delay of $0.5 \mathrm{~ms}$ in the relay response. Subject to this delay, the two variables can individually be used as fault discriminators.

ii. Transient energy is a good fault discriminator for this case of triple-tuned dc filter, just like the HVDC system with the previously considered filters. 


\section{CONCLUSION}

A monopolar LCC-HVDC system has been simulated with three different dc filters using PSCAD $^{\mathrm{TM}} / \mathrm{EMTDC}^{\mathrm{TM}}$. Responses of the system to solid faults occurring at three internal locations and two external locations have been analyzed for three system variables, namely, incremental current, incremental power and transient energy. The results of the study are summarized in Table 2 regarding the suitability of these variables as fault discriminators.

It can be concluded from the table that for HVDC line equipped with cascaded double-tuned dc filter, incremental current, incremental power or transient energy, any one of the three variables, can be used as the fault discriminator. However, for HVDC line having parallel double-tuned dc filter, only transient energy can be used as the fault discriminator. Also, for HVDC line with triple-tuned dc filter, incremental current or incremental power can be used as a fault discriminator by inserting a delay of $0.5 \mathrm{~ms}$ in the relay response, whereas transient energy can be used without inserting any such delay in the response of the relay.

In the cases of cascaded double-tuned and triple-tuned dc filters, where more than one option is available, the final selection of fault discriminator should be made after evaluating the system response on high resistance faults and longer lines. Research has been initiated by the authors in this regard.

Table 2. Summary of Study

\begin{tabular}{cccc}
\hline System Variable & $\begin{array}{c}\text { Cascaded double-tuned dc filter } \\
\text { (Section 2) }\end{array}$ & $\begin{array}{c}\text { Parallel double -tuned dc filter } \\
\text { (Section 3) }\end{array}$ & $\begin{array}{c}\text { Triple-tuned dc filter } \\
\text { (Section 4) }\end{array}$ \\
\hline Incremental Current & Suitable & Not suitable & $\begin{array}{c}\text { Suitable with delay in relay } \\
\text { response }\end{array}$ \\
Incremental Power & Suitable & Not suitable & $\begin{array}{c}\text { Suitable with delay in relay } \\
\text { response }\end{array}$ \\
Transient Energy & Suitable & Suitable & Suitable \\
\hline
\end{tabular}

\section{APPENDIX}

(a). Parallel Double-tuned dc filter

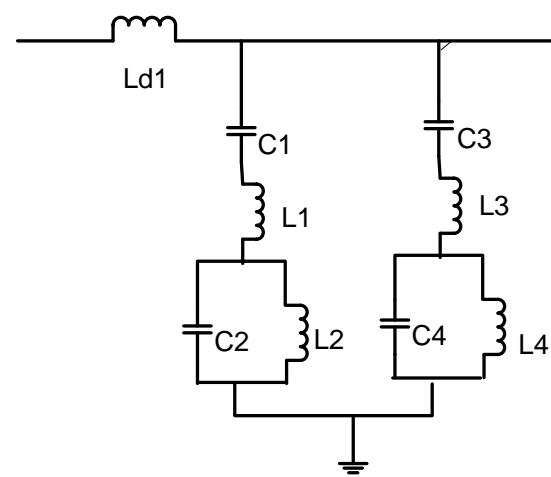

Figure A.1. Configuration of parallel double-tuned dc filter [21]

Following values of filter parameters were considered for the study [21]:

$\mathrm{L}_{\mathrm{d} 1}=0.29 \mathrm{H}, \mathrm{C}_{1}=2 \mu \mathrm{F}, \mathrm{L}_{1}=11.71 \mathrm{mH}$,

$\mathrm{C}_{2}=9.074 \mu \mathrm{F}, \mathrm{L}_{2}=5.874 \mathrm{mH}$,

$\mathrm{C}_{3}=2 \mu \mathrm{F}, \mathrm{L}_{3}=6.46 \mathrm{mH}$,

$\mathrm{C}_{4}=3.752 \mu \mathrm{F}, \mathrm{L}_{4}=11.35 \mathrm{mH}$

(b). Triple-tuned dc filter

(a). Following values of filter were considered for the study [22]:

(b). $\mathrm{L}_{\mathrm{d} 1}=150 \mathrm{mH}, \mathrm{C}_{1}=1.2 \mu \mathrm{F}, \mathrm{L}_{1}=9.345 \mathrm{mH}$, 
(c). $\mathrm{C}_{2}=2.824 \mu \mathrm{F}, \mathrm{L}_{2}=15.919 \mathrm{mH}$,

(d). $\mathrm{C}_{3}=2.647 \mu \mathrm{F}, \mathrm{L}_{3}=4.656 \mathrm{mH}$.

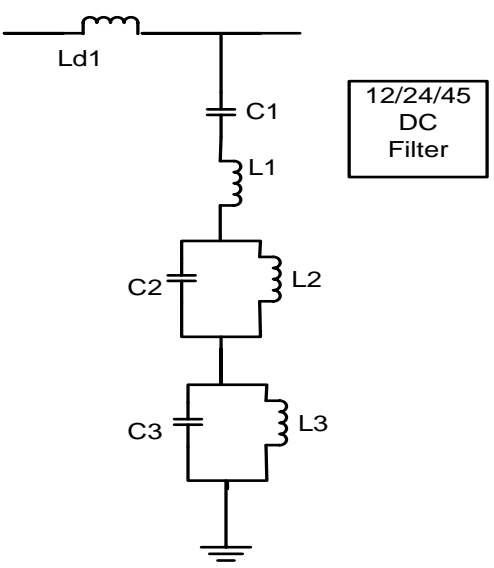

Figure A.2. DC filter configuration for triple-tuned dc filters [22].

\section{REFERENCES}

[1] W Long, S Nilsson, "HVDC transmission: Yesterday and today," IEEE Power and Energy Magazine. Vol. 5, no. 2, pp. 22-31, 2007.

[2] P. Bresesti, WL Kling, RL Hendriks, R. Vailati, "HVDC connection of offshore wind farms to the transmission system," IEEE Transaction on Energy Converters, vol: 22, no. 1, pp. 37-43, 2007.

[3] S. Agarwal, CK. Panigrahi, A. Sahoo, S. Mishra. "A Novel Study on Bipolar High Voltage Direct Current Transmission Lines Protection Schemes," International Journal of Electrical and Computer Engineering, vol. 8 no.4, pp. 1977-1984, 2018

[4] S. Mirhosseini, M. Akhbari, "Wide area backup protection algorithm for transmission lines based on fault component complex power," International Journal of Electrical Power and Energy Systems, vol. 83, pp. 1-6, 2016.

[5] X Lin, Z Li, K Wu, H. Weng, "Principles and implementations of hierarchical region defensive systems of power grid," IEEE Transaction on Power Delivery, vol.24 no. 1, pp. 30-37, 2009.

[6] L. Shang., G. Herold, J. Jaeger, R. Krebs, and A. Kumar. "High-speed fault identification and protection for HVDC line using wavelet technique." In 2001 IEEE Porto Power Tech Proceedings, Porto, Portugal, 2001.

[7] X. Liu, A. H. Osman, and O. P. Malik. "Hybrid traveling wave/boundary protection for monopolar HVDC line." IEEE Transactions on Power Delivery, vol. 24, no. 2, pp. 569-578, 2009.

[8] F. Kong, Z Hao, S Zhang, B Zhang, "Development of a novel protection device for bipolar HVDC transmission lines." IEEE Transactions on Power Delivery, vol. 29, no. 5, pp. 2270-2278, 2014.

[9] X Zheng, T Nengling, Y Guangliang, D Haoyin, "A transient protection scheme for HVDC transmission line." IEEE Transactions on Power Delivery, vol 27, no. 2, pp. 718-724, 2012.

[10] X Zheng, N Tai, JS. Thorp, G Yang. "A transient harmonic current protection scheme for HVDC transmission line." IEEE Transactions on Power Delivery, vol 27, no. 4 pp. 2278-2285, 2012.

[11] J Wu, H Li, G Wang, Y Liang. "An improved traveling-wave protection scheme for LCC-HVDC transmission lines." IEEE Transactions on Power Delivery, vol 32, no. 1, pp. 106-116, 2016.

[12] S Deb, HK Verma "Selection of Fault Discriminators for Unit Protection of Monopolar HVDC Transmission System.

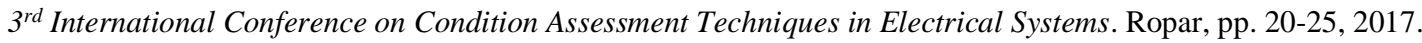

[13] G Shuping, S Guobing, M Zhibin, J Xingfu, "Novel pilot protection principle for high-voltage direct current transmission lines based on fault component current characteristics," IET Generation Transmission Distribution, Vol 9, no. 5, pp. 468-474, 2015.

[14] Kong F, Hao Z, Zhang B. Improved differential current protection scheme for CSC-HVDC transmission lines. IET Generation, Transmission \& Distribution. 2017; 11(4): 978-986.

[15] Li C, Gole AM, Zhao C. A Fast DC Fault Detection Method Using DC Reactor Voltages in HVDC Grids. IEEE Transaction on Power Delivery. 2018; 33(5): 2254-2264.

[16] Cao W, Yin X, Qi X, Wang Y, Liu W, Pan Y. Analysis for DC transmission line harmonics originated from AC 
transformer inrush current and improved method for DC harmonic protection. The Journal of Engineering. 2019; 2019(16): 1056-1061.

[17] Zheng J, Wen M, Chen Y, Shao X. A novel differential protection scheme for HVDC transmission lines. Electrical Power and Energy Systems. 2018; 171-178.

[18] Zhang Y, Li Y, Song J, Li B, Chen X. A New Protection Scheme for HVDC Transmission lines based on the Specific Frequency. IEEE Transaction on Power Delivery. 2019; 34(2): 420-42.

[19] Ma Y, Li H, Wang G, Wu J. Fault Analysis and Traveling-Wave-Based Protection Scheme for Double-Circuit LCC-HVDC Transmission Lines with Shared Towers. IEEE Transaction on Power Delivery. 2018; 33(3): 14791488.

[20] Faruque MO, Yuyan Z, Venkata D. Detailed Modeling of CIGRE HVDC Benchmark System using PSCAD/EMTDC and PSB/SIMULINK. IEEE Transaction on Power Delivery. 2006; 21(1): 378-387.

[21] Luo S, Dong X, Shi S, Wang B. A Directional Protection Scheme for HVDC transmission lines based on Reactive Energy. IEEE Transaction on Power Delivery. 2016; 31(2): 559-566.

[22] Guo J, Wang G, Liang Y, Zeng D. Global-sensitivity-based theoretical analysis and fast prediction of travelling waves with respect to fault resistance on HVDC transmission lines. IEEE Transaction on Power Delivery. 2015; 30(4): 2007-2016. 